

\section{Imagens e imaginários sobre Brasília turística: da Capital Nacional ao patrimônio-territorial}

Images and imagination about Brasilia tourist: of the National Capital to the heritage-territorial

Estephany da Silva Almeida ${ }^{1}$ Rafael Rodrigues Sobreira de Souza ${ }^{2}$ 


\section{Resumo}

Brasília, símbolo da modernidade brasileira, foi projetada por meio do discurso e das ideologias políticas do Brasil. Considerada utópica, a nova Capital utilizou dos recursos simbólicos para lançar sua imagem e garantir a aceitação da população nacional. O projeto de construção de Brasília é algo relativamente antigo, pois a ideia de transferir a Capital para o centro do país vem desde o período em que o Brasil ainda era uma colônia portuguesa. Brasília foi inaugurada na década de 1960 e seu contexto histórico excepcional fez com que fosse inscrita na lista de Patrimônio Histórico da Humanidade. Entretanto, sua dinâmica territorial acabou tornando Brasília uma cidade comum em relação aos problemas sociais que apresenta. Atualmente o Distrito Federal possui 31 Regiões Administrativas, muitas dessas cidades foram criadas no contexto da construção de Brasília, porém essa memória é constantemente negligenciada, projetando apenas a imagem de Brasília como o Plano Piloto. Assim, este trabalho pretende analisar Brasília e seu potencial turístico a partir de seu patrimônio-territorial.

Palavras Brasília; Imagem e Imaginário; Patrimônio Mundial; Patrimônio-Territorial; Turismo.

\section{Abstract}

Brasilia, symbol of modernity in Brazil, was designed by means of speech and of the political ideologies of Brazil. Considered utopian, the new Capital has used the resources to symbolic launch your image and ensure the acceptance of national population. The project for the construction of Brasilia is relatively old, because the idea of transferring the Capital to the center of the country came from the period in which Brazil was still a portuguese colony. Brasilia was inaugurated in the 1960s and their historical context of exception made it on the list of Historic Patrimony of the Humanity. However, its territorial dynamics turned Brasilia a city policy in relation to the social problems it presents. Currently, the Federal District has 31 Administrative Regions, many of these cities were created in the context of the construction of Brasilia, but this memory is constantly overlooked, projecting only the image of Brasilia as the Pilot Plan. Thus, this study aims to analyze Brasilia and its tourist potential from your estate planning.

Keywords: Brasilia; Image and imagination; World Heritage; Territorial Heritage; Tourism. 


\section{INTRODUÇÃO}

Todos os indivíduos estão inseridos em relações sociais e, consequentemente, produzem e constroem a imagem e o imaginário da realidade que os cerca. A imagem é afetiva e é influenciada por nossas ações e reações. Ela surge da experiência empírica. Do contato com o real e das experiências visuais e individuais.

O imaginário é reproduzido por meio das relações sociais e tais relações são repletas de significados. Essa reprodução também está vinculada a busca por uma identidade, busca mediada pelo discurso e pelas imagens. Para Baczko (1985), o imaginário é uma ferramenta e uma estratégia de manipulação social, principalmente, na esfera política. Um dos meios mais comuns de manipulação social é a comunicação, onde destaca-se a mídia.

Neste contexto, como afirma Miranda (1995), mesmo antes de ser construída, Brasília a "Capital da Esperança" sempre esteve coberta de símbolos que compôs e compõe a imagem e o imaginário da Capital Federal. A criação de Brasília foi um pivô imagético para as mudanças que o Brasil precisava ingressar. Além das transformações espaciais que Brasília trouxe para o Centro-Oeste brasileiro ela também reuniu pessoas, culturas e tradições que formam hoje o território brasiliense.

Estrategicamente Brasília foi lançada, por meio do discurso, como imagem da arquitetura moderna, centro do poder nacional e o despertar de um novo Brasil. Atualmente, o quadrilátero do Distrito Federal possui trinta e uma cidades denominadas Regiões Administrativas. Essas cidades possuem dinâmicas, territorialidades e desafios próprios. Algumas delas, como: Planaltina, Taguatinga, Ceilândia, Núcleo Bandeirante, São Sebastião nasceram ou cresceram no contexto da construção de Brasília e guardam partes importantes da história e da memória do Distrito Federal.

Dessa forma, o presente trabalho tem como foco o entendimento de Brasília para além do Plano Piloto. Onde o objetivo principal é analisar a lógica imagética e imaginária que reproduz Brasília e seu patrimônio-territorial, sem desconsiderar os sentidos atribuídos à cidade na lógica de sua construção.

Para alcançar este objetivo foi realizada uma revisão bibliográfica sobre os conceitos abordados e também sobre Brasília e sua construção. Durante a pesquisa ocorreram atividades de campo de aproximação e de profundidade ao Plano Piloto, Vila Telebrasília, Vila Planalto, Museu Vivo da Memória Candanga (Núcleo Bandeirante), Museu Histórico e Artístico de Planaltina, Praça do Relógio (Taguatinga) e ao Arquivo Público do Distrito Federal (ARPDF).

As entrevistas semiestruturadas foram realizadas próximas a Rodoviária do Pla- 
no Piloto por ser um dos principais lugares de cruzamento entre as populações do Distrito Federal e seu entorno. $\mathrm{O}$ uso das entrevistas objetivou-se pela apreensão das imagens e dos imaginários relativo aos moradores, trabalhadores e turistas de Brasília. Foram selecionados 10 entrevistados, escolhidos aleatoriamente, de acordo com a disponibilidade para responder o questionário. Dos entrevistados, dois estavam de passagem por Brasília, um a trabalho e outro a turismo. Apenas um entrevistado nasceu e cresceu no DF. Sendo que os demais eram naturais de outros estados do País, como: Pernambuco, Bahia, Rio Grande do Sul, Minas Gerais, Goiás e Rio de Janeiro. Entretanto, com exceção de dois entrevistamos, que estavam de passagem por Brasília, todos eram moradores permanentes do Distrito Federal com residência no Paranoá, Guará II, Recanto das Emas, Plano Piloto, Ceilândia, Taguatinga e Jardins Mangueiral.

Assim, dividimos este artigo em três capítulos. O primeiro aborda os principais conceitos que tangem o trabalho e alguns símbolos que Brasília apresenta em seu território. O segundo capítulo trata sobre os processos de patrimonialização e suas contradições, analisando o caso de Brasília. E por fim, o terceiro capítulo aborda uma proposta metodológica que sugere uma utopia que valorize e preserve também áreas que estão além do sítio chancelado pela UNESCO.

\section{IMAGEM, IMAGINÁRIO E TERRITÓRIOS URBANOS TURÍSTICOS}

A formação de um imaginário diante das interpretações feitas aos objetos e símbolos é algo inerente ao homem. Segundo Laplantine (2003), a imagem é algo criado mediante o conhecimento empírico e com uma gênese concreta. $O$ imaginário para o autor é um produto da imagem percebida, e é diretamente influenciado pelos sentimentos. Assim, tanto a imagem como o imaginário perpassam o limite do real e o homem as produz e reproduz de acordo com as condições sociais no qual está inserido.

Segundo Orlandi (1994, p. 56), o imaginário fomenta as relações sociais por meio do discurso. Essas relações permitem a organização, significação e a posição do sujeito na sociedade. Dessa forma, para o autor, é pelo imaginário que o indivíduo busca sua identidade e seus objetivos.

Desse modo, a relação do sujeito com o mundo é considerada por Orlandi (1994, p. 56) como uma ideologia. Essa ideologia é vista como o imaginário condicionando a sua existência. "No discurso, o mundo é apreendido, trabalhado pela linguagem [...]. A ideologia é, pois, constitutiva da relação do mundo com a linguagem, ou meIhor, ela é condição para essa condição." 
A ideologia é algo que está presente em todas as realidades sociais e que pode ser intencional ou não. Porém, levando em consideração sua intencionalidade a ideologia está intimamente ligada à mídia e envolvida com o poder. Portanto, é importante entender o papel do discurso para compreender a dinâmica social no processo de formação ideológica.

Segundo Serbena (2003), a ideologia racionaliza o discurso e muitas vezes busca aspectos utópicos e modelos com a intenção de "manipular" uma organização social. Outro aspecto importante que o autor aborda sobre a ideologia é sua função sobre o imaginário, que legitima a necessidade dos sentidos por meios dos símbolos, sonhos, mitos e fantasias.

Além disso, o imaginário traça uma vertente entre o poder e a política juntamente com os interesses sociais e as ideologias. Serbena (2003), afirma que é pelo imaginário que ocorre a legitimação ideológica de um regime político, assim como ocorre a mobilização efetiva das massas. Atualmente, a função do imaginário social para a manipulação das massas é algo muito discutido, principalmente no âmbito político e midiático.

Nessa perspectiva, desde a ideia de sua criação, Brasília tinha a imagem de um Novo Brasil. Segundo James Holston (1993, p.24), essa ideia representava "a mitologia do Novo Mundo [...] como um instrumento de desenvolvimento político e econômico". No entanto, o plano da construção de uma nova Capital só foi posto em prática no Plano de Metas do então presidente Juscelino Kubitschek (1956-1960).

A campanha e o discurso de Juscelino Kubitschek para pôr em prática a ideia de uma nova Capital brasileira foram recheados de simbologias e mitos, que lhe acrescentaram mais credibilidade e adeptos. Segundo Holston (1993, p. 201), a celebração de uma missa, por Dom Carlos Carmelo de Vasconcelos Mota no dia 3 de maio de 1957, que marcava a fundação de Brasília estava simbolicamente vinculada a Primeira Missa de Pedro Álvares Cabral, também no dia 3 de maio, em 1500. Neste sentido, essa analogia histórica relacionada à fundação da Nova Capital brasileira visava "estabelecer uma soberania irradiadora, como o meio para consolidar, civilizar e povoar seu país-continente".

Outra simbologia interpretada por Holston (1993, p. 201) em relação às empreitadas do presidente Juscelino Kubitschek está na sua comparação com Tomé de Souza (primeiro governador-geral do Brasil), onde ambos tiveram visões de um projeto de desenvolvimento. "Na verdade, os dois governantes chegaram antes das populações para as quais construíram suas cidades, e ambos prepararam modelos para suas respectivas 'pólis' antes que estas tivessem cidadãos organizados conforme tais modelos". 
Ainda tinha quem acreditasse que a escolha do local da construção da nova Capital foi por uma profecia de um santo italiano, Giovanni Melchior Bosco (Dom Bosco), que relatava ter sonhado com o surgimento da capital. No sonho de Dom Bosco, a construção da capital ocorreria antes que a segunda geração acabasse, e estaria localizada entre os paralelos 15 e 20, entre a Cordilheira dos Andes e o Oceano Atlântico, esta é a localização exata da instalação de Brasília (COUTO, 2009). Alguns anúncios foram promovidos na época, legitimando essas simbologias.

No período da construção de Brasília a mídia teve um papel importante para sua legitimação. No processo de "recrutamento", que foi uma campanha nacional que o presidente Juscelino Kubitschek promoveu por meio dos principais meios de comunicação da época (imprensa, rádio e televisão), a mídia foi fundamental para atrair pessoas para trabalhar na construção de Brasília.

Essa campanha, segundo Holston (1993, p. 207), trouxe o "entusiasmo pela capital", e foi considerado como o principal símbolo de desenvolvimento do país. A mídia promovia Brasília em vários aspectos, mas as empresas também contribuíram com a construção deste imaginário. Holston (1993, p. 208) descreve alguns exemplos de anúncios e slogans de jornais e revistas que saldavam a nova Capital: "Aqui começa um novo Brasil' - Explosivos Rupturita S. A (indústria de explosivos; 'Brasília: A alvorada de uma nova era - Bimetal Brasil'; 'O marco decisivo no progresso nacional - Mercedes-Benz do Brasil' e 'Brasília: Um novo caminho - Cobrasma S.A.'”

Até mesmo o formato que Brasília tem em seu território, o avião, também é um símbolo que indicava na época a ideia de um país que estava saindo das bases econômicas "atrasadas" e decolando para a modernidade. Além disso, todo o território de Brasília foi pensando e planejado: suas ruas, quadras, o comércio, tornado Brasília neste sentido singular.

As analogias vinculadas a Brasília também estavam ligadas as imagens dos trabaIhadores recrutados, ou como afirma Holston (1993, p. 209) os "bandeirantes do século XX", contando também com o pronunciamento de empresas que promoviam essa imagem: "Eternit saúda os bravos bandeirantes que com sua coragem e sacrifício estabelecerem as fundações da mais moderna cidade do mundo, provando a grande capacidade técnica e a criatividade do povo brasileiro".

No processo de "recrutamento" os "bandeirantes" foram divididos em dois grupos de trabalhadores, os "pioneiros" e os "candangos". Os pioneiros eram considerados os "primeiros", os profissionais qualificados, comerciantes e agricultores. Já os candangos carregavam a imagem oposta dos pioneiros. $\mathrm{O}$ termo candango referia-se aos trabalhadores com pouca ou nenhuma instrução e era considerado um insulto e algo depreciativo. 


\section{Foto 1: Vista da Esplanada dos Ministérios com "Candangos"}

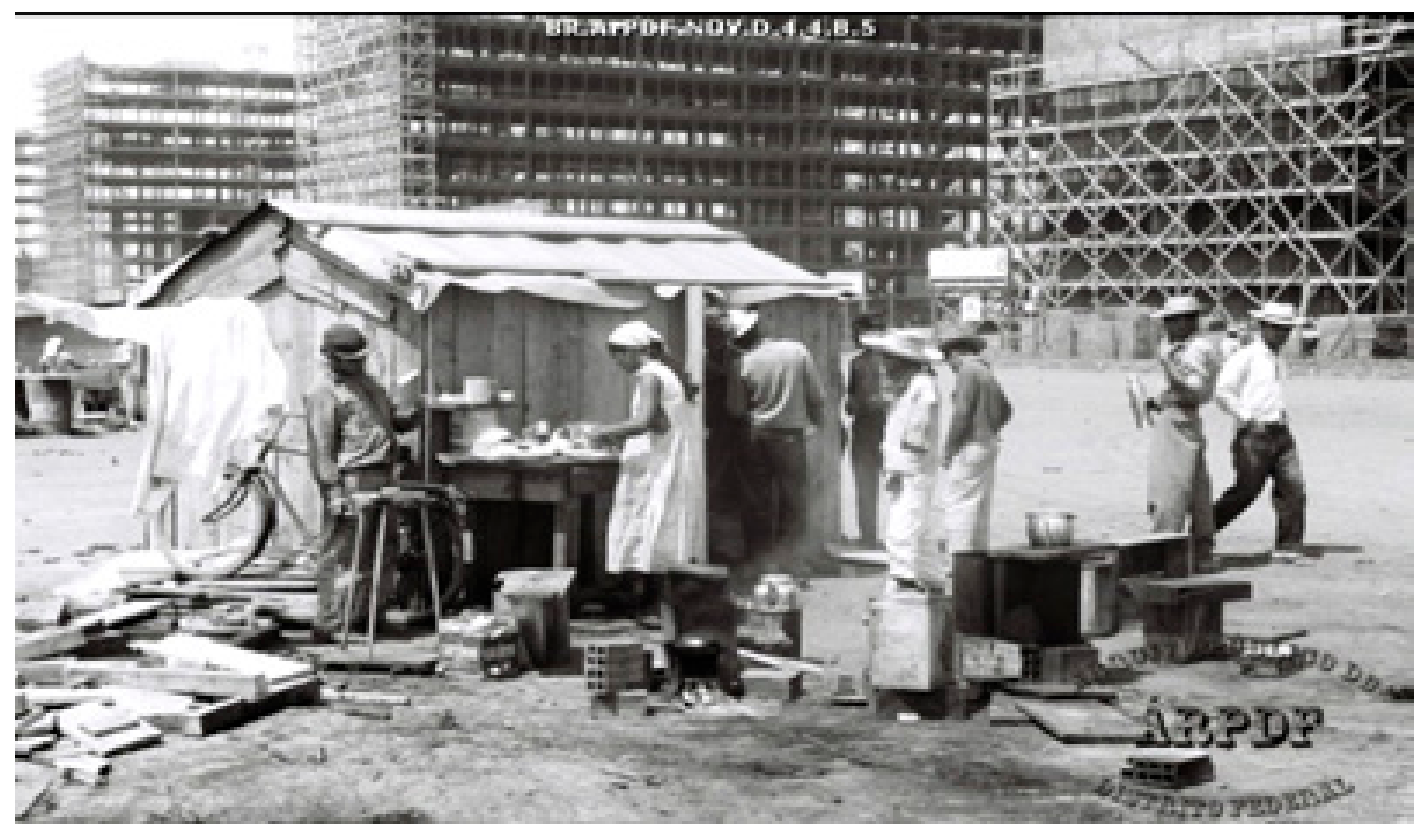

Fonte: ARPDF, 1959.

Inicialmente vistos como "homens comuns", os candangos foram considerados os reais construtores de Brasília, denominados como "titãs anônimos" (ver foto1). Todavia, a imagem se inverteu e os candangos foram vistos como operários pobres e sem instrução que sofreram uma depreciação de sua imagem, por parte das elites locais (pioneiros).

Dessa forma, podemos entender Brasília como uma ideologia legitimada por meio da manipulação do imaginário coletivo. Para Raffestin (1993, p.153) "[...] as 'imagens' territoriais revelam as relações de produção e conseguintemente as relações de poder, e é decifrando-as que se chega à estrutura profunda [...]". Juscelino Kubitschek, durante seu mandato presidencial, fez vários projetos que transformaram a configuração do território brasileiro, assim como: a instalação de novas indústrias, construção de novas estradas e até mesmo Brasília. Costa e Peluso $(2013$, p.4) afirmam que Brasília estava no contexto do desenvolvimento nacional, principalmente no que se refere a indústria automobilística, naval, siderúrgica, petrolífera.

Portanto, a análise do território é ampla e diversificada, entretanto, sua leitura não deve ser dissociada do espaço geográfico. Segundo Milton Santos (1996), a configuração territorial é classificada como a materialização, ou como um conjunto de complexos naturais e sociais. Com o passar do tempo a configuração territorial se modifica, fato identificado nas obras e ações humanas. 
Simbolicamente, Brasília está ligada ao poder do Estado, relacionado às estratégias espaciais, voltado para um maior controle territorial. O Plano de Metas de JK promoveu o que os autores Costa e Steinke (2014) chamam de "poder tentacular", que se refere às estratégias que o governo estabeleceu para integrar todo o território nacional aos demais estados brasileiros, ou seja, Brasília como centro do poder.

Nessa perspectiva Raffestin (1993, p.143-144), em citação a Lefebvre, considera que o território "é um espaço onde se projetou um trabalho, seja energia e informação, e que, por consequência, revela relações marcadas pelo poder. Dessa forma, entende-se o território como estratégias, ações e representações no espaço para uma disputa entre sujeitos, sendo possível identificar várias formas do poder.

Outra questão importante a ser analisada no território são as técnicas, que o caracteriza de acordo com o tempo e o espaço. Para Santos (1994, p. 50), "a materialidade do território é dada por objetos que têm uma gênese técnica [...]", esses objetos técnicos passam a representar um sistema de realizações e funcionalidades, que para o autor estão cada vez mais especializados, promovendo uma "hegemonia" dentro da sociedade e principalmente nas cidades.

Para Costa (2010), o território se comporta mediante as instâncias da sociedade, da economia e cultura-ideológica. Assim cada instância dispõe de um produto, isto de acordo com as necessidades dos "agentes do capital". Tais necessidades são dispostas por dois agentes sociais, o salário e o lucro (respectivamente o trabalhador e o capitalista).

Deste modo, as projeções do imaginário por meio dos símbolos modelam condutas e previsões de mundo na sociedade. Brasília, compreendida em seus vários símbolos, buscava aceitação da população e principalmente o "recrutamento" de trabaIhadores para erguer a nova capital. Essa não era apenas uma estratégia ideológica, mas também uma estratégia política que se fez necessária para uma configuração de novas mudanças sociais e políticas. Assim, o imaginário tem grande importância na compreensão do mundo social, pois ele indica quais as intenções no meio social, no campo político e no exercício do poder em qualquer escala (SERBENA, 2003).

Uma prática social que representa uma sociedade moderna é a cidade, onde também é classificado por Buitoni (2013, p.51), como "a imagem gráfica da nação", ou até mesmo o "espelho do mundo". É nas estruturas urbanas da cidade que os signos estão repletos de significados que permitem a denotação das linguagens, e possibilitam principalmente a sua interpretação (arquitetura, publicidade, moda, rádio, televisão). A leitura do espaço urbano é cada vez mais complexa, visto que suas estruturas e significados acompanham o ritmo da vida contemporânea, um ritmo 
acelerado e em constante mutação.

Para os autores Costa e Steinke (2012, p.3), esse ritmo se dá por um controle territorial que acontece por meio da universalização das coisas, onde prevalece o domínio do simbólico (ordem social) entendido como "efeito de normatização" desempenhado por agentes hegemônicos. Essas relações universalizadas têm como objetivo a busca por universalizar os lugares. Essas relações recriam singularidades, ao modo que "o pensamento essencial que organiza os territórios de identidade e da natureza opera em todas as facetas das relações, em todos os universos sociais [...]". Assim novos sentidos figurativos são designados à linguagem, que são formados pela busca da universalização dos lugares, como exemplo as cidades denominadas "Patrimônio da Humanidade", que é o caso de Brasília.

O território pode ser interpretado de diversas maneiras. Santos (1996) traz a ideia de território usado, cujo objetivo é analisar as atividades que dinamizam o território. Portanto, a cidade pode ser definida como uma fração do território usado e o turismo como uma atividade que dinamiza a cidade.

Segundo Steinberger (2009, p.39), o turismo só pode ser analisado sobre a ótica do território. "Se esse uso não se efetivar não há turismo e, assim, não há o que analisar". Deste modo, a autora afirma que o turismo como uso do território produz o espaço, e isso acontece por meio dos processos sociais que ocorrem de maneira fracionada no território com funções distintas.

O turismo por sua vez, é considerado por vários autores, dentre eles Fratucci (2009, p.121), como uma atividade moderna e capitalista. O autor considera o turismo como um agente espacial, que promove o fluxo de pessoas e de informações, cujo principal objetivo é produzir e consumir espaços. "O turismo manifesta-se através de diversas formas, modalidades e escalas dentro de um mesmo território". Porém, segundo Barreto (2004) grande parte da análise do turismo é meramente ilustrativa e descritiva, pois desconsidera as facetas que envolvem essa atividade econômica.

O turismo, como uma atividade de lazer, traça perfis de consumidores por meio do marketing. Nesses perfis, o turista é classificado de acordo com critérios que fracionam os turistas em relação as possibilidades e demandas de consumo. Assim, como afirma Deprest (1997, p.21), "o turismo surge com diversificações rapidamente dominadas pelo mercado do turismo para captar clientelas"

Para Costa (2010, p.27), o turismo "refuncionaliza os espaços" que foram produzidos ao longo da história de um determinado lugar. E segundo a lógica do trabalho humano (com salário, décimo terceiro, férias e folgas), o tempo livre passa a ser ob- 
jeto de exploração para a atividade turística. "O trabalho, assim, escraviza o homem e não o liberta; o tempo livre para o lazer torna-se, pois, nesse contexto de repressão laboral, uma conquista a ser estabelecida e não um direito facilmente atingível."

Costa (2010) afirma que a estética das cidades é o principal alvo para o turismo, onde as características variam no grau de valorização, cenarização ou banalização. Em crítica ao processo de turistificação das cidades, o autor considera que há uma negligência com os fatores históricos e culturais, ou seja, há uma "desvalorização cultural" em prol da acumulação capitalista.

Outra crítica feita por Costa (2010, p. 52) diz respeito ao imaginário coletivo que está sendo desvirtuado em função da "indústria" do turismo nas cidades históricas. Uma vez que, elas estão sendo "revalorizadas" para atender a demanda do turismo. “Assim, é o histórico 'poder do dinheiro' que permitiu uma das condições para a representação arquitetônica, processualmente, da antiguidade às cidades mundiais turísticas; permitiu a passagem da necessidade de sobrevivência à possibilidade da acumulação material".

Dessa forma, o turismo se apropria de algumas características históricas que compõe o espaço ocasionando a dialética entre a manutenção e a transformação (COSTA, 2010). Ou seja, há uma refuncionalização do patrimônio a serviço do turismo. No caso de Brasília a atividade turística foi algo quase inevitável. Afinal a cidade monumental foi projetada e constituída por meio de vários símbolos que incorporaram ao imaginário coletivo o sentimento de nacionalidade. No entanto, para compreender Brasília e seus territórios turísticos é preciso ir além do sítio tombado pelo IPHAN e chancelado pela UNESCO.

\section{BRASÍLIA: A CIDADE MODERNISTA E A DUALIDADE PATRIMONIAL}

Tendo consciência de que as transformações que o homem impõe ao espaço ocorrem de forma continua e marcam os distintos modos de produção, por intermédio dos processos técnicos, é possível afirmar que a paisagem é fruto da cultura e das ações humanas em diferentes momentos históricos. Nesse sentido, concordamos com Santos (1989) que o espaço é formado pela acumulação desigual de tempos.

"O espaço portanto é um testemunho; ele testemunha um momento de um modo de produção pela memória do espaço construído, das coisas fixadas na paisagem criada. Assim o espaço é uma forma, uma forma durável, que não se desfaz paralelamente à mudança de processos; ao contrário, alguns processos se adaptam às formas preexistentes enquanto que outros criam novas formas para se inserir dentro delas" (SANTOS, 2002, p.173). 
Vale ressaltar que as ações humanas deixam marcas na paisagem que referem-se a diferentes períodos históricos, Santos (2002) denomina essas marcas espaciais como rugosidades. Logo, as rugosidades inscritas na paisagem são frutos de ações humanas passadas que ainda estão presentes nos mais diferentes espaços.

De acordo com Santos (2002), as rugosidades são as formas cristalizadas do passado que fornecem informações sobre o território e sobre os modos de vida de uma determinada localidade. Essas marcas de tempos pretéritos, que ainda fazem parte do arranjo espacial atual, são como arquivos do passado que carregam informações valiosas das atividades humanas sobre o território.

Portanto, as rugosidades são testemunhos de características herdadas do passado que ainda continuam inscritas na paisagem coexistindo com novas formas espaciais. E é nesse sentido que há uma extrema necessidade de preservar e garantir a manutenção desses registros, pois eles fazem parte do que restou de tempos pretéritos e compõem a memória e a identidade do lugar.

Todavia, a busca pela preservação e proteção destes testemunhos enfrenta uma dualidade. Por um lado existe o real sentido da patrimonialização, preservar o que diz respeito a história e a cultura de um povo, por outro há a mera valorização de certos espaços em função de um desenvolvimento integrado e sistematizado. Ou seja, ao mesmo tempo em que a preservação do patrimônio promove um suporte para a memória e para a identidade de um lugar ela também faz parte do complexo sistema capitalista.

"[...] o número de monumentos inscritos na lista do patrimônio mundial tende a se transformar num índice de prestígio internacional e a se tornar objeto de disputa, muitas vezes sem que os critérios de seleção dos bens patrimoniais sejam bem entendidos pelos países interessados" (CHOAY, 2006, p.208).

Esse é um dos fatores responsáveis pela mercantilização patrimonial na sociedade atual. Essa mercantilização está vinculada com a atividade turística que explora certos atrativos, em detrimento de outros, visando o lucro (BENI, 1997). Para que essa prática ocorra atribui-se valores e significados a certas porções do território, formas espaciais e costumes com o intuito de valorizar e explorar o espaço que se torna também turístico.

Segundo Costa (2010, p.20), a definição de "valor" apresenta vários significados. Dentre eles há o valor de uso, valor de troca e o valor simbólico que refere-se ao valor atribuído a algo por meio de uma intencionalidade. Seguindo pela abordagem do turismo, o valor simbólico dispõe de uma "ultravaloração econômica dos lugares 
turísticos, [...] um adendo para se produzir marcos de distinção de novas mercadorias para a 'indústria' do turismo".

Nessa perspectiva, Choay (2010) afirma que a atribuição de valores simbólicos aos lugares e seus costumes permitiram a expansão das práticas patrimoniais ao redor do mundo. Fato que, na dinâmica capitalista, resulta em apropriação e consumo do espaço pelo turismo.

O consumo dos lugares pelo turismo pode ser entendido como uma "refuncionalização" do "espaço produzido historicamente" em escala global. Uma vez que, com o avanço das transformações impostas pelo capitalismo várias atividades são designadas ao turismo que modifica e "articula os lugares com o mundo" (COSTA, 2010, p.27).

As atividades turísticas respondendo as demandas capitalistas exploram, produzem (BARRETO, 2004) e consomem espaços. Dentre os espaços que são explorados pelo fenômeno turístico encontramos as cidades patrimoniais, que por meio de forças dominantes, em diversas escalas, criam novas territorialidades que muitas vezes impõem dinâmicas externas a realidade local.

De acordo com Choay (2006), essa exploração das cidades patrimoniais gera efeitos contrários e secundários. Um exemplo desses efeitos é o aumento da pressão imobiliária que exclui a população local financeiramente vulnerável dos lugares que habitam e dos benefícios do turismo. Já a população que consegue permanecer no local dificilmente tem condições de manter suas atividades tradicionais e cotidianas. $\mathrm{O}$ que interfere em aspectos identitários, pois geram enormes perdas nas tradições e costumes locais.

Frente ao que foi apresentado algumas indagações surgem a respeito do processo de patrimonialização. $\mathrm{O}$ ato de preservar é designado a quem? Para que serve? Em que medida a prática do turismo é democrática? Inquietações, compartilhadas por diversos autores, que ainda parecem estar longe de acabar uma vez que o turismo, guiado pelo capitalismo, está constantemente se reinventando e consumindo/produzindo novos espaços de exploração.

Compreendemos que a grande questão em relação aos bens materiais e imateriais é que eles não se limitam apenas as formas patrimoniais oficializadas. As formas e culturas que não possuem a "garantia" estatal de preservação também registram os processos históricos ocorridos no espaço e guardam memórias relacionadas as vivências que ocorreram no território onde estão inseridas.

Portanto, adotamos uma visão crítica em relação ao atual processo de patrimonialização. Onde o turismo, respondendo a interesses capitalistas, se apropria e 
explora áreas patrimoniais negligenciando e desconsiderando as dinâmicas territoriais que as circundam.

Após esta breve discussão teórica sobre a dualidade existente no processo de patrimonialização discutiremos essa realidade no contexto de Brasília, cidade patrimonial, intitulada pela UNESCO como Patrimônio Mundial da Humanidade, que apresenta de forma enfática as contradições que o turismo impõe ao território.

Partindo das entrevistas, realizadas durante a pesquisa, a maioria dos entrevistados, exceto um, sabiam que Brasília foi tombada e reconhecida como Patrimônio da Humanidade. Eles afirmaram que esse título agrega valores a cidade. Nesse sentido, destacamos o ponto de vista do entrevistado 7: "Sempre soube que Brasília foi tombada. E esse título agrega valores na medida em que contribui para a conservação e proteção do seu projeto urbanístico inicial".

Para a UNESCO, a atual Capital da República Federativa do Brasil é uma cidade singular. Brasília é caracterizada como uma cidade modernista, por seu arrojado projeto e formas arquitetônicas, e foi construía em um ritmo frenético no centro do território brasileiro para sediar o núcleo político e burocrático do Brasil.

Em contrapartida, o entrevistado 3 esclarece sua opinião sobre Brasília ser tombada: "Não sabia que Brasilia era patrimônio. E eu acho que deveria agregar valores sim [...] qualquer lugar que seja patrimônio da humanidade deve ter seu valor, mas [...] a humanidade mesmo não está sendo preservada. [...] É muito irrelevante qualquer lugar ser tombado, pois Brasília ser tombada não interfere na vida de ninguém".

Portanto, a importância de Brasília não se limita apenas aos monumentos e traçados modernistas que a compõem. A memória de sua construção e a vivência cotidiana da população, que empregam sentido e vida a suas formas, também são riquezas imensuráveis que merecem ser preservadas e difundidas.

Infelizmente essa não é uma realidade presente em Brasília, onde o Estado e a iniciativa privada limitam a preservação e a manutenção aos monumentos e ao sítio tombado pelo IPHAN. Ou seja, o Plano Piloto de Brasília recebe os benefícios da patrimonialização em detrimentos de outros locais que também fazem parte do acervo histórico e cultural de Brasília.

Essa negligência e visível abandono são percebidos principalmente em locais que estão fora do sítio tombado (ver fotos 2 e 3). Todavia, ocorrem também em espaços no interior do sítio tombado ligados aos antigos operários que ergueram a monumental cidade e em seguida foram afastados da modernidade que Brasília representava. 
Foto 2: Construção da Esplanada dos Ministérios (1956-1960)

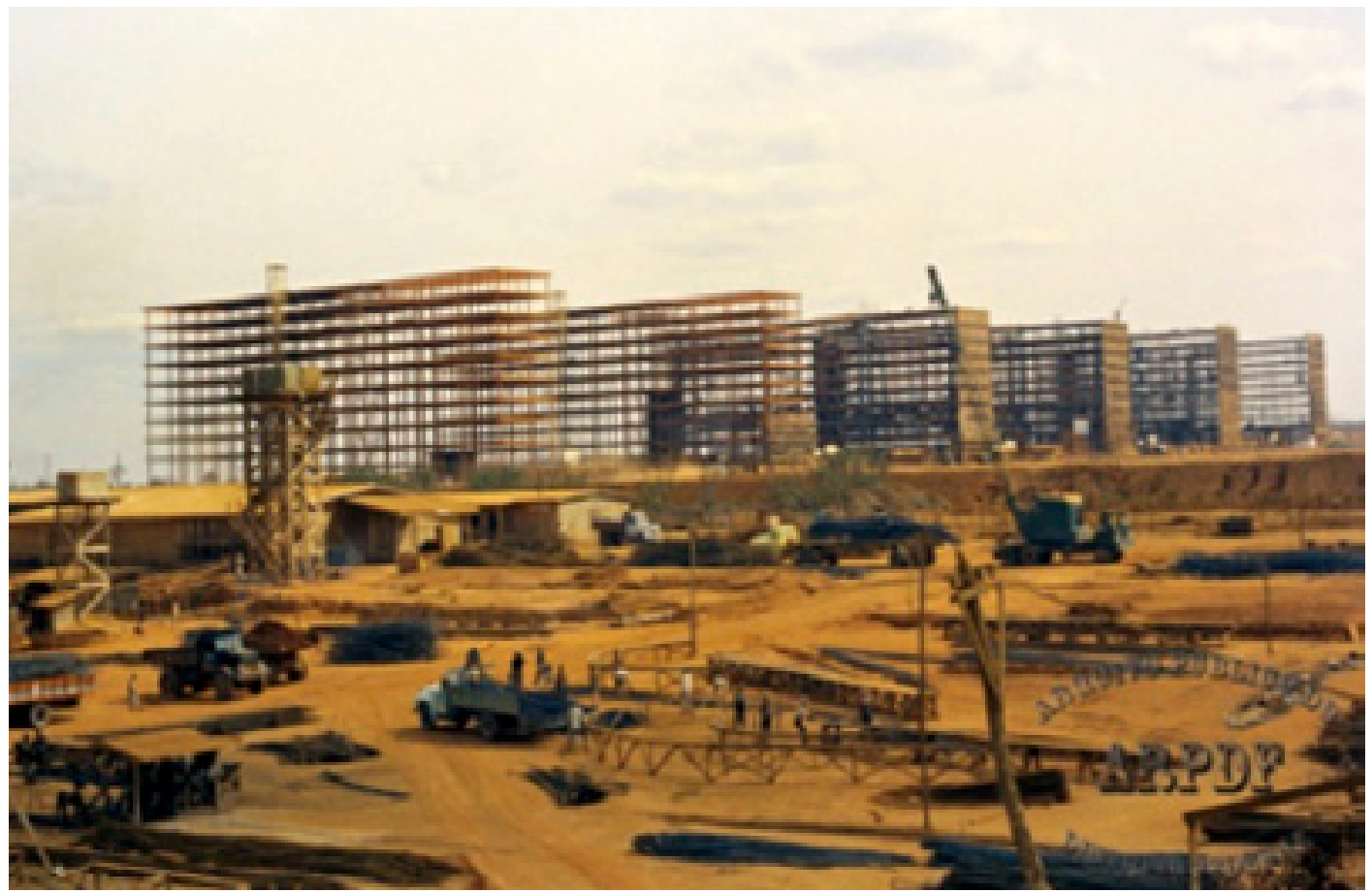

Fonte: APDF.

Foto 3: Construção do Congresso Nacional (1956-1960)

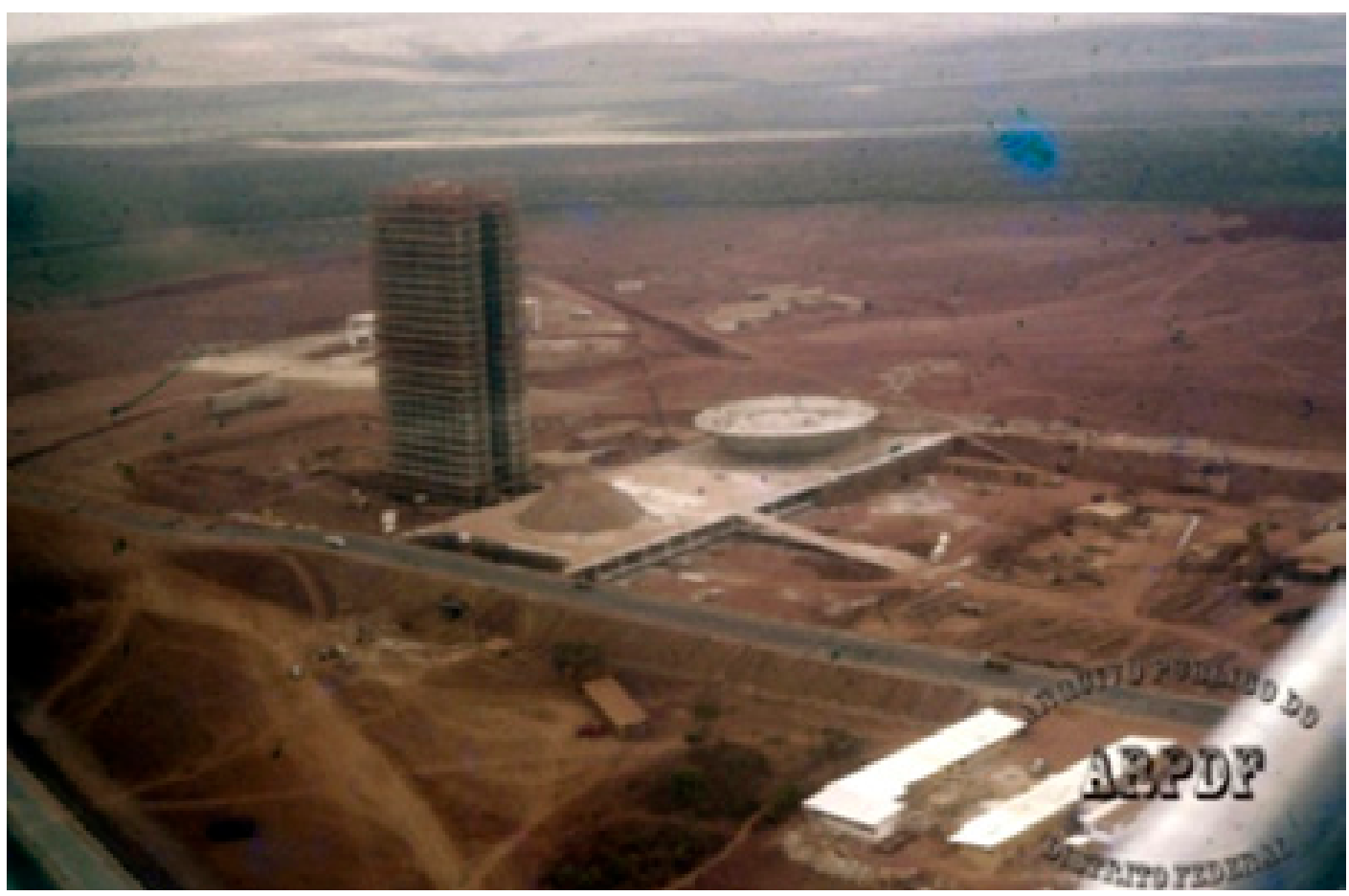

Fonte: APDF. 
Como exemplos dessas áreas temos a Vila Telebrasília e a Vila Planalto. Estes antigos acampamentos oferecem elementos sobre a história da construção de Brasília e uma rica memória de luta e resistência. Contudo, tais locais não recebem a mesma atenção e proteção que o Plano Piloto, pois negam a utopia imaginada pelas elites políticas e econômicas para Brasília.

A situação se agrava quando analisamos bens históricos e culturais que estão fora do sítio tombado. Estes patrimônios, oficializados ou não, por não estarem localizados na Brasília ideal, mas na Brasília real, aparentemente estão esquecidos pelo poder público e fora dos interesses capitalistas.

No que se refere ao turismo, tais áreas não se encontram nos roteiros turísticos da Capital. O que reforça a mistificação, legitimada pela mídia, de Brasília apenas como cidade-capital e cidade-patrimonial. Esta mistificação transmite para o público nacional e internacional que Brasília se limita apenas a Esplanada dos Ministérios e ao Plano Piloto. Portanto, a forma como as atividades turísticas vem sendo praticadas na localidade ocasionam prejuízos no entendimento das territorialidades brasilienses e da totalidade que Brasília representa.

Em contraposição o turismo quando praticado de forma consciente e com responsabilidade social pode amenizar desigualdades socioespaciais historicamente construídas, pois gera emprego e renda para a população local e contribui com a preservação de sua história e memória (BENI, 1997).

Sobre a imagem vendida de Brasília, a maioria dos entrevistados afirmou que a mídia vende somente as coisas boas de Brasília. Destacamos o pondo de vista do entrevistado 4, onde ele retrata a imagem vendida de Brasília, mas em uma perspectiva crítica. Ele chama a atenção para possíveis roteiros turísticos que incluam as demais cidades que compõem Brasília em sua totalidade: "a mídia vende seus encantos, pelos pontos turísticos, mas deveria mostras os outros lados de Brasília, levar os turistas para a favela, para mostrar o lado da população marginal".

Portanto, o entendimento de Brasília, a preservação e o turismo não podem continuar restritos ao Plano Piloto. E necessário valorizar e preservar também a história e a memória, que vem do passado e do presente, daqueles que cotidianamente constroem a Capital do Brasil. Este entendimento pode parecer utópico, mas é uma utopia necessária. 


\section{BRASÍLIA, PATRIMÔNIO DA HUMANIDADE E O UTOPISMO PA- TRIMONIAL TERRITORIAL}

Diante do exposto acreditamos na utopia de que é possível valorizar e preservar também o que está fora do patrimônio oficializado. Nesta proposta, o turismo praticado de maneira consciente e com responsabilidade social pode contribuir com a preservação de bens, materiais e imateriais, que dizem respeito aos que cotidianamente constituem o território.

Costa (2016, p.1) enfatiza o poder que as utopias têm de promover mudanças. Uma vez que, os modelos considerados utópicos são bases para transformações socioespaciais. E diante do sistema econômico vigente, o capitalismo, que produz e reproduz contradições "a utopia ressurge como uma nova saída crítica".

Para Costa (2016), os Utopismos Patrimoniais são formados, metodologicamente, por três utopismos. O primeiro, fundamental para nossa análise, diz respeito ao utopismo patrimônio-territorial que visa concretizar formas e memórias urbanas/ rurais que possuem como protagonistas as pessoas que cotidianamente atribuem significado ao território vivido.

O utopismo patrimônio-territorial tem como ideologia o rompimento com as origens colonizadoras, ou seja, "[...] o patrimônio-territorial resgata, situa e ressignifica, espacialmente, o que resiste na América Latina: do índio sacrificado, do negro escravizado, da mulher oprimida, da cultura popular desprestigiada, dos recursos territoriais expropriados, ou seja, aquela 'face oculta' da modernidade" (COSTA, 2016, p.7).

Costa (2016) afirma que o utopismo patrimônio-territorial tem como objetivo desmascarar a colonialidade, vinculada ao poder e ao controle colonial, em relação às imagens da modernidade:

"O utopismo patrimônio-territorial quer inverter a noção de uma Amé-
rica Latina como civilização apartada do Ocidente. A imposição da ideia
de Hemisfério Ocidental como Atlântico Norte [Ocidente não envolveria,
então, América Latina, África e Ásia] assegura o conceito de civilização
ocidental e, paradoxalmente, instiga forças ocultas no imaginário criollo
de Hemisfério Ocidental, isto é, vêm à tona forças ameríndias e afro-ame-
ricanas alimentadas pela difusão técnica de informações que apresen-
tam e reforçam, cada vez mais, seu lugar no mundo" (COSTA, 2016, p.8).

Esses territórios, vinculados a população de menor poder aquisitivo, estão em muitos casos nas áreas periféricas dos núcleos patrimoniais. No contexto da América Latina saberes, tradições, costumes e formas inscritas na paisagem, que compõem a identidade desses lugares, estão sendo negligenciadas e perdidas.

Como vimos anteriormente, no caso de Brasília, a riqueza histórica e cultural que também se encontra fora do Plano Piloto enfrenta o descaso de autoridades públicas 
e a descrença dos agentes promotores de turismo. De acordo com Peluso e Candido (2006), no Distrito Federal o descuido em relação a preservação dos bens materiais e imateriais se estende inclusive para patrimônios tombados por órgãos oficiais.

A situação pode ser constatada quando se compara as condições de preservação dos bens localizados no centro de Brasília, o Plano Piloto, com os bens que se encontram nas regiões periféricas da Capital. Como resultado de atividades de campo apresentamos dois exemplos de patrimônios oficiais negligenciados pelo Estado por estarem fora da utopia imaginada para Brasília, o Museu Vivo da Memória Candanga e o Museu Histórico e Artístico de Planaltina.

O Museu Vivo da Memória Candanga (ver foto 4), localizado na Região Administrativa do Núcleo Bandeirante, é o único museu do Distrito Federal que possui um acervo que aborda a história de Brasília na perspectiva do "candango". O museu foi tombado pela SUPHAC ${ }^{3}$ em 1985 como patrimônio cultural e recentemente, no ano de 2015, também foi tombado IPHAN. Apesar de sua importância o museu sofre com a falta de manutenção e investimentos por parte do Governo do Distrito Federal.

\section{Foto 4: Museu Vivo da Memória Candanga - Antigas instalações do Hospital} Juscelino Kubitschek.

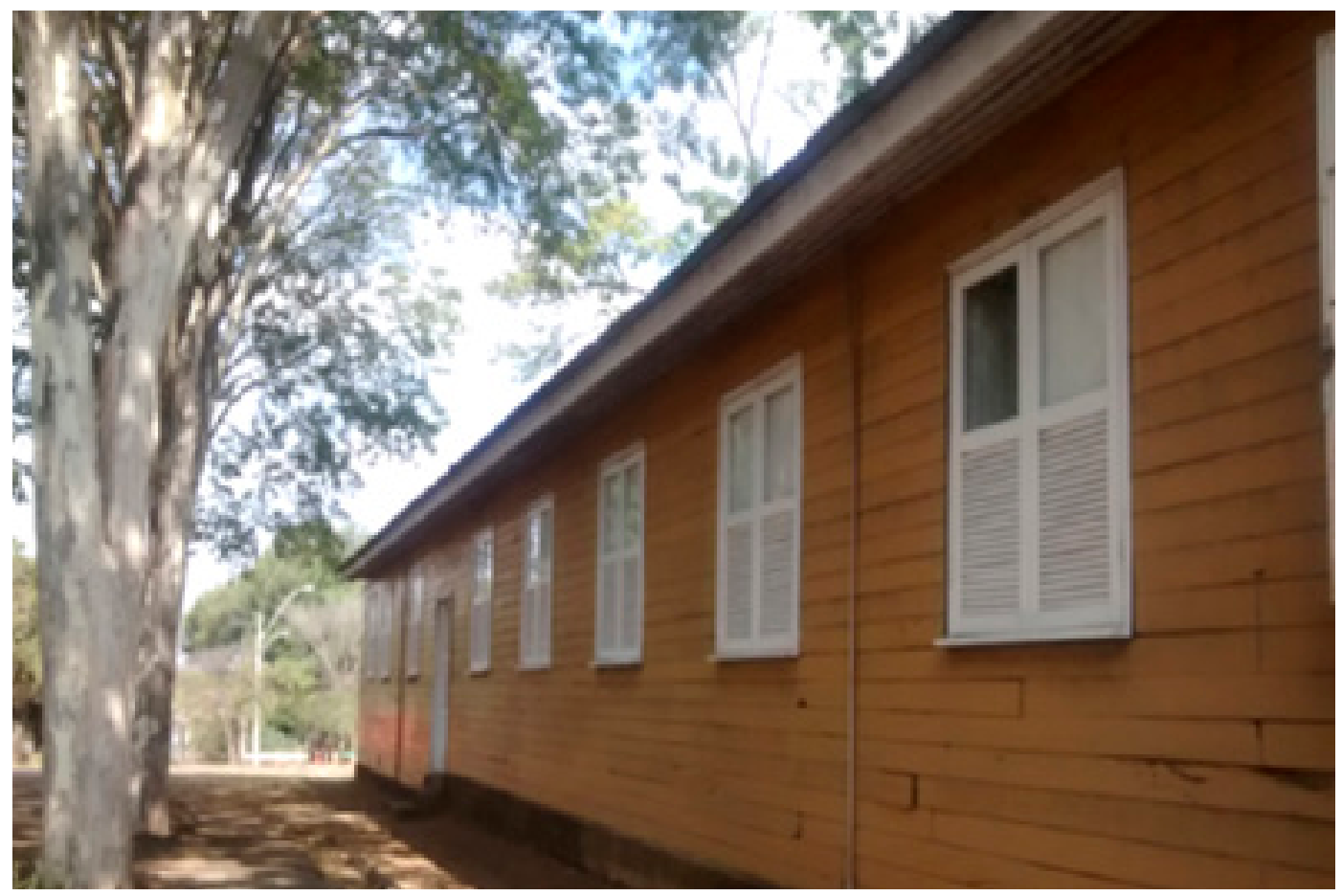

Fonte: Estephany Almeida, 2015.

3 SUPHAC - Subsecretaria do Patrimônio Histórico, Artístico e Cultural. 
Foto 5: Museu Histórico e Artístico de Planaltina.

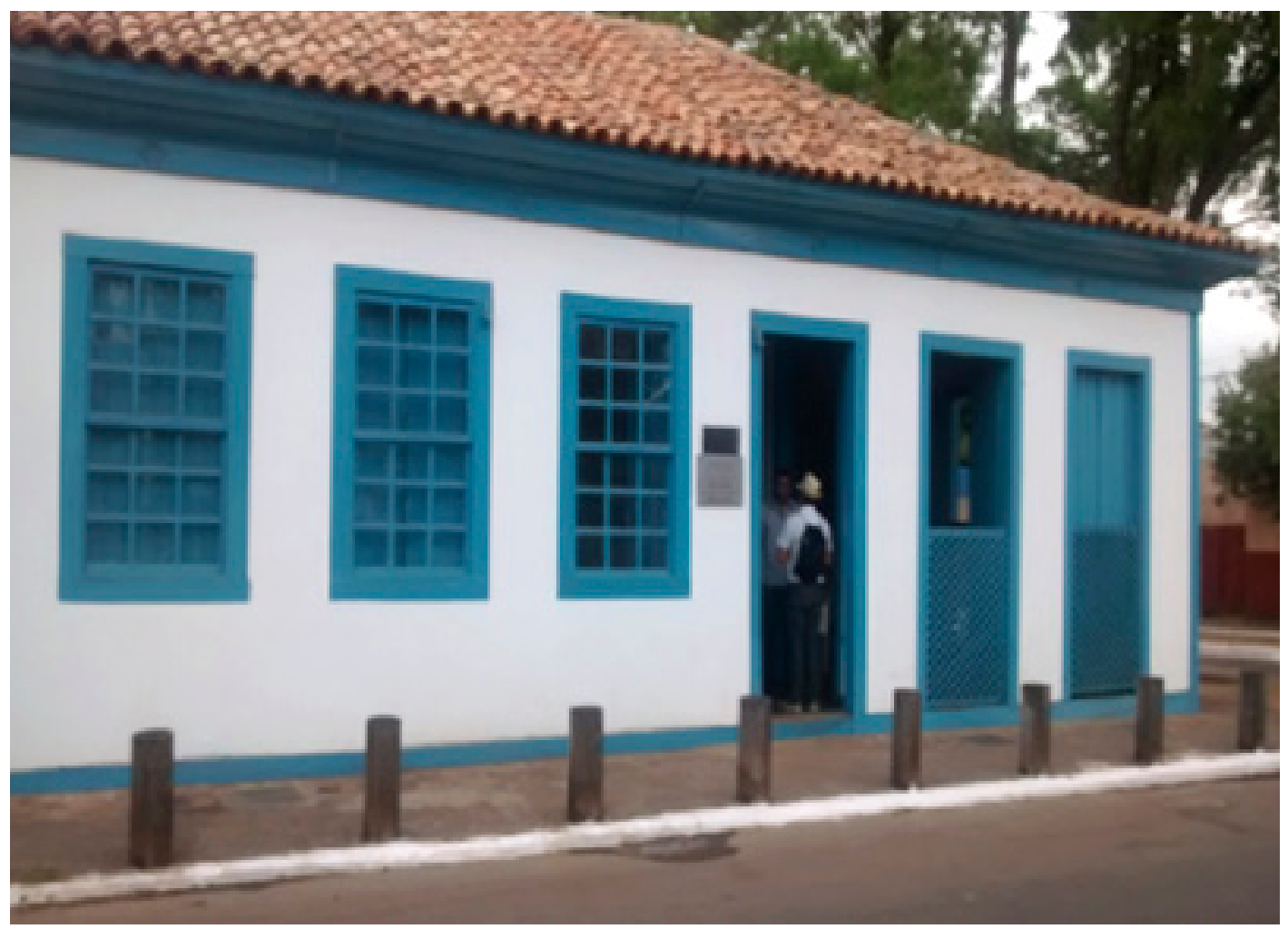

Fonte: Estephany Almeida, 2015.

O segundo exemplo, o Museu Histórico e Artístico de Planaltina (ver foto 5), foi recentemente restaurado, mas ainda não possui a devida atenção do poder público e raramente recebe visitações. O museu foi tombado pela SUPHAC em 1971 e, mesmo estando sob tutela da DEPHA ${ }^{4}$, foi durante muito tempo abandonado pelo Estado.

Os dois Museus apresentam características em comum. Dentre elas destacamos a importância histórica e cultural que carregam, o tombamento por órgãos oficiais e a negligência sofrida por parte do Estado. Outro fator em comum é que nenhum dos dois estão na rota do turismo em Brasília.

O mapa a seguir mostra a densidade patrimonial no território do Distrito Federal:

4 DEPHA - Diretoria de Patrimônio Histórico e Artístico. 


\section{Mapa 1. Densidade Patrimonial no Distrito Federal.}

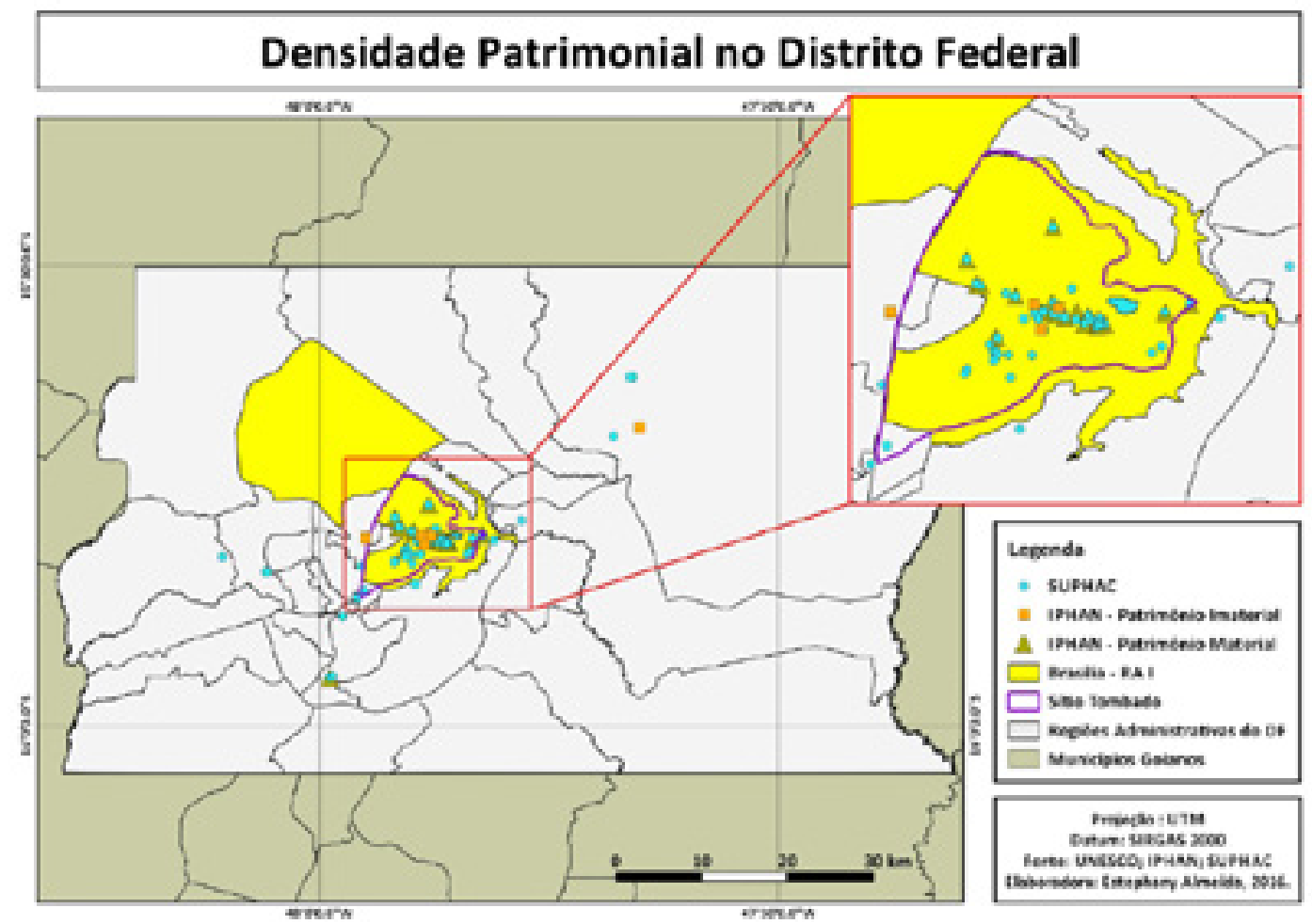

Estephany Almeida, 2016.

Nele podemos perceber a concentração de patrimônios tombados no centro de Brasília e, que existem alguns patrimônios fora do sítio tombado pela UNESCO ${ }^{5}$. Esses patrimônios, apesar de serem tombados, assim como nos exemplos anteriores, não possuem a mesma atenção e reconhecimento que os patrimônios localizados no Plano Piloto. Todavia, é importante salientar que essas áreas são de grande importância para a história e para a formação cultural da população do Distrito Federal.

Retomando a ideia de patrimônio-territorial, proposta por Costa (2016), e considerando Brasília no contexto de modernidade e colonialidade podemos perceber que as intencionalidades simbólicas do Estado estão voltadas para um desenvolvimento territorial baseado em um parâmetro mundial centralizador. Parâmetro este que gera desigualdades e negligencia aspectos locais e regionais.

Portanto, Apesar de ser uma cidade-capital utópica, Brasília apresenta em seu território desigualdades socioespaciais que se equiparam as demais cidades brasileiras. Essa desigualdade tem raízes históricas de relações de poder impressas em

5 Alguns patrimônios imateriais não estão contidos no mapa, pois não possuem referência geográfica. 
todo o território do Distrito Federal, inclusive no que diz respeito às formas e significados do Plano Piloto em contraponto com as formas e significados das Regiões Administrativas.

Enfatizamos que essas localidades também apresentam valores históricos e culturais que poderiam ser incluídos na rota turística de Brasília. Contudo, o valor que esses lugares possuem não deve ser voltado apenas para o mercado do turismo, mas para a própria comunidade local. Uma vez que consolidam a identidade e o sentimento de pertencimento ao lugar.

Negar as cidades que fizeram parte da construção de Brasília é o mesmo que negar a identidade do território e negar a imagem dos reais edificadores da Capital. Afinal foi para estas cidades que os construtores de Brasília foram forçados a ir após o término da construção.

Quanto ao ponto de vista dos entrevistados sobre as outras Regiões Administrativas todos afirmaram que o Distrito Federal, em sua totalidade, possui a mesma importância que o Plano Piloto. As respostas transcritas dos entrevistados 2 e 5 , trazem o ponto de vista sobre o território vivido pela população pobre no Distrito Federal. Entrevistado 2: "As outras RAs são importantes também, por que lá que é o lugar das pessoas mais pobre, assim né?!"; Entrevistado 5: "Pra mim as outras RAs são mais importantes que Brasília, pois é lá que mora a maioria da população pobre".

"O utopismo patrimônio-territorial afronta, por meio de sujeitos, de
grupos e de bens culturais situados e em situação espacial, a ideo-
logia que legitima, na história, a colonialidade do poder e do saber.
Quando essa ideologia distorce, firma e diferencia lugares, a consci-
ência e o conhecimento sobre tais lugares, contraditoriamente, ela
estimula resistências. O utopismo patrimônio-territorial rebate a
ideologia enquanto 'falsa consciência de uma situação', por uma ou-
tra sociedade e por um imaginário social da transformação popular
a partir de símbolos territoriais resistentes à colonialidade: arte, reli-
gião, saberes, modos de vida, assentamentos de grupos subalternos
urbanos e rurais. Esse utopismo reafirma, para denunciar e indicar
novo caminho, uma América Latina dividida em classes, etnias e re-
giões, tudo reverberado na essência da grandiosidade de obras, fa-
tos e sujeitos históricos que resistem nos lugares: indígenas, negros,
mulheres, pobres urbanos que atestam a diversidade das memórias
nacionais" (COSTA, 2016, p.8).

Brasília em sua essência perpassa os limites de seus monumentos, símbolos e representações sociais, políticas e econômicas. A análise sob a ótica de quem vive Brasília cotidianamente, comparando com os discursos e com a imagem vendida da capital, fornecem os instrumentos para a compreensão da lógica e dos significados das estruturas culturais e simbólicas de seu território. 
Enxergar Brasília em sua totalidade está percebê-la para além do Plano Piloto. Portanto, é preciso compreender o processo de formação histórica das cidades que a circundam e que formam o arranjo territorial do Distrito Federal. Talvez assim o preconceito e as desigualdades socioespaciais sejam amenizadas na Capital da República.

Desse modo, a preservação que um tombamento acarreta não pode continuar limitando-se apenas a áreas definidas por interesses do capital turístico (BARRETO, 2004). É necessário preservar também o que diz respeito aos que de fato formam o quadro territorial das regiões patrimoniais.

Esta proposta adquire valor uma vez que, assim como Costa (2016), entendemos as regiões periféricas dos núcleos patrimoniais latino-americanos como lugares portadores de fatos e sujeitos históricos que, como os patrimônios oficiais e chancelados, também carregam valores simbólicos e identitários que precisam ser preservados e difundidos.

\section{CONSIDERAÇÕES FINAIS}

Toda e qualquer cidade tem sua história e seu valor. Porém esse valor é seletivo em relação ao que deve ser valorizado, preservado e visitado. Brasília chancelada pela UNESCO como Patrimônio da Humanidade, reproduz a imagem e o imaginário de uma capital desigual.

O utopismo patrimônio-territorial, proposto por Costa (2016), é uma utopia necessária quando levamos em consideração uma proposta de mudança para o atual quadro de valorização dos lugares turísticos. É preciso valorizar o que está fora da rota turística, é preciso confrontar por meio da luta e resistência cultural o que tange grande parte do território nacional.

Brasília não pode ser compreendida apenas pelo seu plano urbanístico, formulado por Lúcio Costa. Entender a dinâmica da cidade perpassa os limites urbanos e, segundo Costa et. al (2013, p.328): “(...) a totalidade da cidade, em essência, só pode ser alcançada na junção entre os elementos concretos que favorecem a produção do imaginário urbano e o próprio imaginário sobre a cidade (...)."

Assim, a imagem vendida do Plano Urbanístico de Brasília nos faz pensar sobre as reais intencionalidades em concentrar as atenções para essa localidade. Afinal, ao redor de Brasília existe um acervo cultural, artístico, histórico que podem ser levados em consideração no processo de ressignificação da identidade nacional. 


\section{REFERÊNCIAS BIBLIOGRÁFICAS}

BARRETO, M. "As ciências sociais aplicadas ao turismo". In: SERRANO, Célia et alii. Olhares contemporâneos sobre o turismo. 3a ed. Campinas: Papirus, 2004, p.17-18. BARRETO, M. Manual de iniciação ao estudo do turismo. Campinas: Papirus, 1997. BENI, M. Análise estrutural do turismo. São Paulo: Senac, 1997.

BUITONI, D. H. S.; COSTA, C. R. (Org.). Enquanto a cidade dorme. In.: A cidade e a imagem. 01. ed. Jundiaí - SP: Editora In House, 2013. v. 01. 348 p.

CHOAY, F. A alegoria do patrimônio. 4 ed.São Paulo: Estação Liberdade: UNESP, 2006. COSTA, E. B et al . Metropolização, patrimonialização e potenciais de conflitos socioterritoriais em Brasília - DF. Espaço e Geografia (UnB), v. 15, p. 325-367, 2013.

COSTA, E. B.; PELUSO, M. L.. Imaginário urbano e 'situação territorial vulnerável' na Capital do Brasil. Biblio 3w (Barcelona), v. XXI, p. 1-36, 2016.

COSTA, E. B. A concretude do fenômeno turismo e as cidades-patrimônio mercadoria - Uma abordagem geográfica. Rio de Janeiro: Livre Expressão, 2010.

COSTA, E. B. Utopismos patrimoniais pela América Latina - resistências à colonialidade do poder. In: XIV Colóquio Internacional de Geocrítica, 2016, Barcelona. Las utopías y la construcción de la sociedad del futuro, 2016. v. 1. p. 1-30.

COUTO, J.G. P. As profecias de Dom Bosco. In: A Mensagem codificada sobre o Brasil nas Profecias de Dom Bosco e outros temas brasileiros e sul-americanos (Org.). Belo Horizonte, Mazza edições, 2009. p. 20-24.

DEPREST, F. Inquérito sobre o turismo de massa: a ecologia face ao território. Lisboa: Instituto Piaget, 1997.

FRATUCCI, A. C. Os lugares turísticos: territórios do fenômeno turístico. Geographia, v. 2, n. 4, p. 121-133, 2009.

HOLSTON, J. A Cidade modernista: uma crítica de Brasília e sua utopia. São Paulo: Companhia das Letras, 1993.

LAPLANTINE, F. O que é imaginário. São Paulo: Brasiliense, 2003.

MIRANDA, Antônio. Brasília utópica (visão e revisão). Brasília: Thesaurus, 1985.

SÁNCHEZ, F. A reinvenção das cidades para um mercado mundial. Chapecó: Argos, 2003.

ORLANDI, E. P. Discurso, imaginário social e conhecimento. Aberto, v. 14, n. 61, p. 53-9, 1994. 
RAFFESTIN, C. Por uma geografia do poder. São Paulo: Editora Ática, 1993.

SANTOS, M. A natureza do espaço - Técnica e tempo. Razão e emoção. São Paulo: Hucitec, 1996.

SANTOS, M. Pensando o espaço do homem. São Paulo: HUCITEC, 1989.

SANTOS, M. A natureza do espaço. São Paulo: Hucitec, 1996.

SANTOS, M. Técnica, espaço, tempo: globalização e meio técnico-científico informacional. São Paulo: Hucitec, 1994.

SANTOS, M. Pensando o espaço do homem. São Paulo: HUCITEC, 1989.

SERBENA, C. A. Imaginário, ideologia e representação social. Cadernos de Pesquisa Interdisciplinar em Ciências Humanas (UFSC), Florianópolis, v. 52, p. 2, 2003.

STEINBERGER, M. (Org.) Territórios turísticos no Brasil Central. Brasília: LGE, 2009. 